\title{
Mapeando a situação educacional no Estado De Sergipe
}

\author{
Cláudia da Mota Darós Parente \\ Juliano Mota Parente
}

\begin{abstract}
Resumo
O presente artigo analisa aspectos histórico-legais da política educacional brasileira, apresentando os principais desafios para a consolidação do novo Plano Nacional de Educação, em construção. A partir disso, o artigo concentra-se na descrição de alguns indicadores educacionais, mapeamento a realidade educacional do estado de Sergipe. O estudo focaliza dados relativos à educação infantil, ao ensino fundamental e à formação de professores, mostrando déficits históricos na Educação Básica. Por meio desse panorama, pretende-se contribuir para o conhecimento das condições atuais da educação no estado, bem como para a visualização de problemas e desafios. Como resultado do estudo, pretende-se mostrar a importância de pesquisas no âmbito da política educacional no estado de Sergipe, de modo a contribuir para a melhoria da qualidade da oferta educacional.
\end{abstract}

Palavras-chave: Política Educacional, Sergipe, Educação Básica.

\section{Describing the educational policy in the state of Sergipe}

\begin{abstract}
This article examines historical and legal aspects of educational policy in Brazil, presenting the main challenges for the consolidation of the new National Education Plan, currently under construction. From this, the article focuses on the description of some educational indicators, describing the educational reality in the state of Sergipe. The study focuses on indicators for early childhood education, to primary education and teacher training, showing historical deficits in basic education. In describing data on education in the state of Sergipe, contextualizing it within the framework and illustrates some national educational policies implemented in the state. As a result of the study is intended to show the importance of research into the educational policy in the state of Sergipe, in order to contribute to improving the quality of educational provision.
\end{abstract}

Key-words: Educational Policy, state of Sergipe. 
O presente estudo tem como objetivo descrever alguns indicadores educacionais, mapeamento a realidade educacional do estado de Sergipe. Em termos metodológicos, compreende a análise da legislação educacional brasileira, aliada à análise estatística da situação da educação no estado. Tomando-se como referência a Sinopse Estatística da Educação Básica (BRASIL, 2009b) e a Sinopse do Professor (BRASIL, 2009c) elaboradas pelo Instituto Nacional de Estudos e Pesquisas Educacionais do Ministério da Educação (INEP/ MEC) e dados do Instituto Brasileiro de Geografia e Estatística (IBGE - 2009a), o presente estudo pretende, por meio da pesquisa quantitativa, apresentar alguns dados da realidade educacional do referido estado. Para melhor delimitação da análise, o estudo abrangerá as seguintes áreas: educação infantil, ensino fundamental e formação de professores.

A análise estatística tem como pano de fundo a análise político-legal do contexto educacional brasileiro atual, privilegiando a transição entre o Plano Nacional de Educação, Lei n ${ }^{0}$ 10.172/2001 e o novo Plano Nacional de Educação, discutido amplamente na Conferência Nacional de Educação - CONAE/2010, em construção. Com base na explicitação de alguns aspectos principais da legislação educacional brasileira e na exposição sobre o contexto atual de formulação no novo Plano Nacional de Educação, importa analisar a situação educacional do estado de Sergipe, verificando os principais problemas e desafios que se colocam para a melhoria da qualidade da educação no estado.

O presente estudo toma como suporte o referencial teórico da área de políticas públicas, compreendendo a análise estatística como subsídio para a política educacional. (RUS PEREZ, NASCIMENTO E PARENTE, 2002)

Deseja-se chamar a atenção para a importância de estudos que tragam à tona a realidade educacional, a fim de que seja possível a formulação e a implementação de políticas públicas efetivas para a educação (SANCHES, 2002; BARDACH, 2001). A difusão de estudos com caráter diagnóstico pode impulsionar a entrada de determinados temas na
Agenda Política, propiciando debates e ações na área educacional. (VIANA, 1988)

\section{Política Educacional Brasileira: desafios atuais}

A análise da história da educação brasileira mostra o atraso na implantação dos sistemas de ensino, no estabelecimento de políticas públicas para a educação e na definição de princípios como a igualdade, a gratuidade, a universalização e a obrigatoriedade do ensino. (ROMANELLI, 1999; FÁVERO, 1996; VEIGA, 2007)

De acordo com o objetivo deste estudo, importa observar alguns enunciados da legislação educacional brasileira em vigor e dos planos educacionais elaborados na última década, destacando seus limites e possibilidades no enfrentamento dos problemas educacionais.

A Constituição Federal Brasileira de 1988 explicita os princípios que devem nortear a educação brasileira, dos quais se destacam: igualdade de condições para o acesso e permanência na escola e gratuidade do ensino público em estabelecimentos oficiais. Entre os deveres do Estado estão:

educação básica obrigatória e gratuita dos 4 (quatro) aos 17 (dezessete) anos de idade, assegurada inclusive sua oferta gratuita para todos os que a ela não tiveram acesso na idade própria; (...) educação infantil, em creche e pré- escola, às crianças até 5 (cinco) anos de idade. (BRASIL, 1988, art. 208, alterado pela $\mathrm{EC} \mathrm{n}^{\circ} 53 / 2006$ e $\mathrm{EC} \mathrm{n}^{\circ} 59 / 2009$ )

Conforme a Lei de Diretrizes e Bases da Educação Nacional, Lei no 9.394/1996, a Educação Brasileira é composta pela Educação Básica (Educação Infantil, Ensino Fundamental e Ensino Médio) e pela Educação Superior. A Educação Infantil deve ser oferecida em creches e pré-escolas, sendo sua oferta de responsabilidade dos municípios. O Ensino Fundamental, com duração de 9 anos, deve ter início aos 6 anos de idade, conforme nova redação 
do artigo 32, alterado pela Lei $\mathrm{n}^{0} 11.274 / 2006$. A responsabilidade pelo Ensino Fundamental deve ser compartilhada por estados e municípios. (SAVIANI, 1997; CURY, 2002; LIBÂNEO, OLIVEIRA E TOSCHI, 2007)

O Plano Nacional de Educação, Lei n ${ }^{\circ}$ 10.172/2001, define diretrizes e metas para todos os níveis e modalidades de ensino, formação de professores, financiamento e gestão. Após seus quase 10 anos de vigência, muitas de suas metas não foram alcançadas, demonstrando a insuficiência de políticas, ações e recursos para resolver os problemas educacionais. A principal crítica ao Plano refere-se ao seu processo de formulação, ao percentual do Produto Interno Bruto (PIB) aplicado na educação e aos vetos realizados pelo então presidente Fernando Henrique Cardoso. (SAVIANI, 1998; SAVIANI, 2007)

Em sua análise crítica do PNE, Saviani (2007) destaca o necessário aumento de recursos financeiros para a educação brasileira:

Eis a questão. $\mathrm{O}$ aumento significativo e imediato dos recursos financeiros é posto como fator indispensável para o enfrentamento satisfatório dos problemas educacionais sendo, pois, condição sine qua non para o êxito do Plano. É assim, a meta das metas, um a priori, já que se constitui como a condição prévia e necessária de viabilidade de todas as demais metas. (p. 298)

Em 2007, foi lançado o Plano de Desenvolvimento da Educação (PDE), sustentando-se em seis pilares:

i) visão sistêmica da educação, ii) territorialidade, iii) desenvolvimento, iv) regime de colaboração, v) responsabilidade e vi) mobilização social - que são desdobramentos conseqüentes de princípios e objetivos constitucionais, com a finalidade de expressar o enlace necessário entre educação, território e desenvolvimento, de um lado, e o enlace entre qualidade, equidade e potencia- lidade, de outro. O PDE busca, de uma perspectiva sistêmica, dar conseqüência, em regime de colaboração, às normas gerais da educação na articulação com o desenvolvimento socioeconômico que se realiza no território, ordenado segundo a lógica do arranjo educativo - local, regional ou nacional. (BRASIL, 2007b, p. 11-12)

Tendo em vista o lançamento do Plano de Desenvolvimento da Educação (PDE) em meio ao esquecimento do Plano Nacional de Educação (PNE), muitas críticas foram feitas ao governo de então e às suas estratégias.

Conforme Camargo, Pinto e Guimarães (2008)

O processo de elaboração do PDE constitui ainda uma incógnita, mas há várias hipóteses a esse respeito. Uma delas é a de que houve uma "encomenda" ao MEC para realizar algo semelhante ao PAC e, como este é coordenado pela própria ministra Dilma Rousseff, o mesmo deveria ser coordenado pelo ministro da Educação. Outra é que nomes fortes no Partido dos Trabalhadores, com diferentes projetos para o MEC, disputavam o ministério no segundo mandato do presidente Lula (no primeiro mandato, Fernando Haddad foi antecedido por Cristovam Buarque e Tarso Genro) e que, por esta razão, o PDE seria uma medida "de contenção" inclusive com vistas a manter o ministro e seu staff em seus cargos. (p. 822)

Os autores destacam ainda alguns aspectos do PDE: indícios de que foi elaborado às pressas e ausência do aporte de recursos financeiros por parte da União para consecução dos objetivos anunciados. Ou seja,

não existe previsão minimamente fundamentada dos custos das quaren- 
ta ações propostas. Observa-se ainda que consta entre elas uma série de ações que são anteriores ao PDE e que são apresentadas como frutos desse "plano", algumas das quais já vê sendo implementadas há vários anos e outras que estão em discussão, como o Fundeb e o Piso Salarial Nacional dos Profissionais da Educação. (p. 827)

Em 2009, foi lançado o Documento Referência da Conferência Nacional de Educação intitulado "Construindo o Sistema Nacional Articulado de Educação: o Plano Nacional de Educação, diretrizes e estratégias de ação”. Tal documento foi base para a discussão nas audiências públicas, nas Conferências Municipais, Intermunicipais, Estaduais de Educação, realizadas durante 2009, e na Conferência Nacional de Educação realizada em 2010.

Conforme o documento,

A CONAE deverá, portanto, constituir-se em espaço social de discussão da educação brasileira, articulando os diferentes agentes institucionais, da sociedade civil e dos governos, em prol da construção de um projeto nacional de educação e de uma Política de Estado. Assim, é fundamental garantir ampla mobilização e participação democrática nas conferências municipais e estaduais, assegurando mais representatividade e participação na Conferência Nacional. (BRASIL, 2009d, p. 4)

O modelo das Conferências ofereceu boa margem para que se constituíssem em espaços sociais de discussão da educação e esse pareceu ser seu principal ponto positivo e também seu principal desafio. Em todas as fases da CONAE, estima-se a participação de 3,5 milhões de pessoas, cerca de $2 \%$ da população brasileira. Durante a Conferência Nacional de Educação, realizada em março e abril de 2010, foram aprovadas 677 emendas ao texto inicial.
A Conae constituiu-se, assim, num espaço democrático de construção de acordos entre atores sociais, que, expressando valores e posições diferenciadas sobre os aspectos culturais, políticos, econômicos, apontam renovadas perspectivas para a organização da educação nacional e para a formulação do Plano Nacional de Educação 20112020. (BRASIL, 2010)

Além disso, uma das principais discussões em todas as fases da CONAE, diz respeito à definição do custo-aluno-qualidade, de modo a assegurar uma educação de qualidade com base na necessidade e não no que está disponível em termos de recursos financeiros.

De acordo com Abicalil (2009)

A CONAE é um espaço privilegiado para que se possa avaliar e articular as definições da Lei de Diretrizes e Bases da Educação Nacional - LDB, do PNE e do próprio PDE, propondo-se alterações e mudanças nestes instrumentos de política pública. Entre as mudanças necessárias está a realização plena de um regime de cooperação entre as diversas instâncias da gestão educacional. A regulação do regime de cooperação e das formas de articulação entre os entes federados, seus respectivos sistemas autônomos e a organização de um Sistema Nacional Articulado de Educação, torna-se indispensável. (p. 3-4)

É o que também destaca Saviani (2009):

No que se refere à construção do Sistema Nacional de Educação propriamente dito, o ponto de referência é o regime de colaboração entre a União, os Estados/Distrito Federal e os Municípios, estabelecido pela Constituição 
Federal. A implementação do regime de colaboração implicará uma repartição das responsabilidades entre os entes federativos, todos voltados para o mesmo objetivo de prover uma educação com o mesmo padrão de qualidade a toda a população brasileira. Assim, deixam de ter sentido os argumentos contra o sistema nacional baseados no caráter federativo que pressupõe a autonomia de estados e municípios. (p. 29)

Finda a CONAE e diante do Documento Final, fruto de discussões e debates realizados em todo o país, é imprescindível que toda a sociedade esteja atenta aos encaminhamentos do legislativo para a construção e votação do Novo Plano Nacional de Educação, a fim de que os principais avanços defendidos pelo Documento não se percam em disputas políticas que não estejam respaldadas na defesa da qualidade social da educação.

\section{A Situação Educacional de Sergipe: alguns indicadores}

Sergipe é o menor estado brasileiro em termos territoriais (21.910 Km2), apresentando uma população de aproximadamente dois milhões de pessoas. Bom seria se os problemas educacionais fossem proporcionais ao seu tamanho, mas não é a realidade encontrada neste estudo. Comparando-se com as médias nacionais, o estado ainda precisa realizar inúmeros esforços para colocar a sua população na escola, garantindo o acesso à educação escolar a quem não teve na idade própria, ampliar a oferta em todos os níveis e modalidades de ensino e garantir formação mínima de qualidade aos professores.

Conforme dados do Censo Escolar de 2009, o estado de Sergipe soma 608.616 matrículas na Educação Básica, distribuídas em 2.475 estabelecimentos de ensino, públicos e particulares. No que se refere aos níveis e modalidades de ensino, as matrículas estão distribuídas na Educação Infantil (12,6\%), no Ensino Fundamental (62,7\%), no Ensino Médio $(13,9 \%)$ e respectivas modalidades de ensino: Educação Especial (0,6\%), Educação de Jovens e Adultos $(9,9 \%)$ e Educação Profissional $(0,4 \%)^{1}$.

Os alunos matriculados pertencem a diferentes faixas etárias e sua grande maioria (57,7\%) pertence à população de 6 a 14 anos, sucedida pela população de 15 a 17 anos, representando $17,2 \%$ das matrículas. Em relação a essa distribuição, destaca-se que $3,1 \%$ dessas matrículas pertencem à população com mais de 29 anos (19.054 pessoas).

As redes municipais de ensino são as principais responsáveis pela oferta da Educação Básica no estado de Sergipe (50\%), seguidas pela rede estadual (36\%) e da rede particular (14\%).

As matrículas da Educação Básica concentram-se, na sua maioria, nas escolas urbanas (77\%). Das matrículas rurais (139.504), 91\% está sob a responsabilidade dos municípios.

Em Sergipe existe apenas um estabelecimento indígena, pertencente à rede estadual e responsável por 103 matrículas. Existem também 23 estabelecimentos em área remanescente de quilombo, atendendo 4.215 matrículas, sob a responsabilidade, na sua maioria, da esfera municipal (85\%).

O analfabetismo na população do estado de Sergipe chega a $16,9 \%$ contra $10 \%$ no Brasil, considerando a população com 15 anos ou mais. Se verificarmos o analfabetismo funcional em Sergipe, ou seja, a pessoa que foi alfabetizada, mas não consegue realizar tarefas simples como interpretar um texto ou fazer operações matemáticas, esse número amplia-se para $26,5 \%$ contra $21 \%$ no Brasil. (BRASIL/IBGE, 2008)

Estes dados demonstram a difícil situação em que se encontra a educação no estado de Sergipe em relação à oferta e ao atendimento na educação básica. Todos indicam a necessidade premente de políticas públicas para melhoria do quadro educacional.

\section{O Atendimento na Educação Infantil}

Em Sergipe, na Educação Infantil, conforme dados de 2009, existem 76.845 matrículas em 1.708 es- 
tabelecimentos, sendo 8.679 matrículas em creches (11\%) e 68.166 matrículas em pré-escolas (89\%).

No que se refere ao ente responsável pela oferta educacional, o estado segue a mesma lógica nacional de concentração da oferta da educação infantil na esfera municipal (74\%), tendo em vista a responsabilidade legal dos municípios na oferta deste nível de ensino. Conforme a Lei de Diretrizes e Bases da Educação Nacional, "os Municípios incumbir-se-ão de (...) oferecer a educação infantil em creches e pré-escolas". (BRASIL, 1996, artigo 11, inciso V)

A análise das matrículas nas creches mostra a fragilidade na oferta de educação para a população de 0 a 3 anos, representando apenas $11 \%$ das matrículas na Educação Infantil, conforme apontado anteriormente. Embora isso ocorra em todo o território nacional é possível perceber que o estado convive com um déficit educacional acentuado nesta faixa etária.

No que se refere à esfera responsável pela oferta educacional em creches, $81 \%$ das matrículas concentram-se nas redes municipais de ensino. Cabe destacar que o estado de Sergipe não apresenta grande iniciativa da esfera privada (19\%), como ocorre no país (34\%).

Quanto à oferta na pré-escola, percebe-se claramente a municipalização das matrículas (73\%), assim como ocorre no país (75\%). A esfera privada é responsável por $26 \%$ das matrículas no estado, um pouco acima da média nacional que é de $23 \%$.

O Censo de 2009 registra a existência de 23.640 matrículas na Educação Infantil rural, distribuídas em 1.078 estabelecimentos de ensino, sendo que destes $10 \%$ são creches e $98 \%$ são pré-escolas ${ }^{2}$.

Das 1.572 matrículas em creches rurais, 97\% são de responsabilidade das redes municipais de ensino; das 22.068 matrículas na pré-escola rural, 98\% são de responsabilidade das redes municipais de ensino.

Vê-se, portanto, os inúmeros desafios que se colocam para a Educação Infantil no estado de Sergipe, principalmente, no que diz respeito à ampliação da oferta. O Plano Nacional de Educação, no que se refere à Educação Infantil, anuncia 26 metas. Em termos de acesso e ampliação da oferta na Educação Infantil, indica a necessidade de
Ampliar a oferta de educação infantil de forma a atender, em cinco anos, a $30 \%$ da população de até 3 anos de idade e $60 \%$ da população de 4 e 6 anos (ou 4 e 5 anos) e, até o final da década, alcançar a meta de $50 \%$ das crianças de 0 a 3 anos e $80 \%$ das de 4 e 5 anos.

Tendo em vista os poucos avanços que houve no cumprimento das metas do $\mathrm{PNE}$, como resultado das discussões presentes na CONAE, reforça-se a preocupação com esta etapa de ensino, frente aos atrasos históricos em todo o país. Por isso, o documento referência da CONAE indica como necessidades prementes:

A consolidação de políticas, diretrizes e ações destinadas à educação infantil, sobretudo considerando a obrigatoriedade a partir dos 04 anos, via coordenação efetiva e atuante dos órgãos da União, estados, Distrito Federal e municípios, com a ampliação, apoio e otimização dos processos de organização, gestão e universalização gradativa desta etapa da educação básica; a realização do censo da educação infantil, garantindo que todas as instituições de educação infantil, públicas e privadas sejam incluídas no Censo Escolar e em outros levantamentos de informações educacionais; a garantia de que o atendimento das crianças seja feito exclusivamente por profissionais devidamente habilitados, conforme a legislação vigente; (...) a ampliação da oferta de educação infantil pelo poder público, extinguindo progressivamente $o$ atendimento por meio de instituições conveniadas. (BRASIL, 2009d)

\section{O Atendimento no Ensino Fundamental}

No Ensino Fundamental de Sergipe, conforme dados do Censo de 2009, existem 381.811 matrí- 
culas, sendo 216.021 nos anos iniciais do Ensino Fundamental (57\%) e 165.790 nos anos finais do Ensino Fundamental (43\%). Do total de matrículas, 64,4\% das matrículas concentrava-se na esfera municipal, $22,2 \%$ na esfera estadual e $13,3 \%$ na esfera particular. No Brasil, essa distribuição é bem parecida, representando $68,2 \%$ das matrículas na rede municipal, 19,3\% nas redes estaduais, 12,4\% na rede particular e 0,04\% na rede federal.

Essa distribuição condiz com os preceitos legais de responsabilidade compartilhada entre os entes federativos (estados e municípios) na oferta do Ensino Fundamental, bem como com a possibilidade de coexistência de instituições públicas e privadas de ensino.

De acordo com a LDB,

Os Estados incumbir-se-ão de [...] definir, com os Municípios, formas de colaboração na oferta do ensino fundamental, as quais devem assegurar a distribuição proporcional das responsabilidades, de acordo com a população a ser atendida e os recursos financeiros disponíveis em cada uma dessas esferas do Poder Público. (BRASIL, 1996, artigo 10 , inciso II)

Do percentual de alunos do Ensino Fundamental no estado de Sergipe, 84,5\% concentram-se na faixa etária de 6 a 14 anos, seguida de 12,5\% na faixa etária de 15 a 17 anos. Chama atenção o fato de que 2,7\% dos alunos do Ensino Fundamental concentram-se na faixa etária de 18 anos ou mais, evidenciando clássicos problemas educacionais: entrada tardia na escola, reprovação, distorção idade-série, analfabetismo.

O desmembramento do Ensino Fundamental possibilita verificar mais de perto esses problemas. Nos anos iniciais, apenas 72,3\% dos alunos pertencem à faixa etária de 6 a 10 anos, sendo que 24,8\% já pertencem à faixa etária de 11 a 14 anos. Nos anos finais do Ensino Fundamental, 66,7\% correspondem à faixa etária de 11 a 14 anos, sendo que 26,3\% estão na faixa etária de 15 a 17. Ainda conforme dados de 2009, existem 8.701 matrículas em Programas de
Correção de Fluxo no estado de Sergipe, distribuídas nas redes municipais e estadual.

É evidente, portanto, a incidência da distorção idade-série em Sergipe. A partir da década de 1990, disseminaram-se em todo o país, inúmeras políticas e experiências no combate à distorção idade-série, entre elas, a implementação de programas de aceleração de aprendizagem. (PARENTE, 2006)

As classes de aceleração foram criadas para a regularização do fluxo escolar daqueles alunos que foram vítimas das repetências múltiplas, atingindo altos índices de distorção idade-série, bem como de alunos que, por vários motivos, entraram tardiamente na escola.

Não é objetivo deste estudo analisar as razões e as conseqüências das políticas formuladas e/ou implementadas no estado de Sergipe. Deseja-se apenas ilustrar algumas ações desenvolvidas no âmbito do estado, relacionadas ao enfrentamento dos problemas educacionais expostos.

Os Programas “Acelera" e "Se Liga" são programas de correção de fluxo desenvolvidos pela Secretaria Estadual de Educação de Sergipe em parceria com o Instituto Ayrton Senna. Os Programas existem, no Brasil, desde 1997 e 1999, respectivamente. Em Sergipe foram implantados em 2005.

O Programa "Acelera" tem como objetivo "contribuir para que o aluno, em um ano, alcance o nível de conhecimento esperado para a primeira fase do Ensino Fundamental, de maneira que possa avançar em sua escolaridade". O Programa "Se Liga" tem como principal objetivo, "em um ano, alfabetizar crianças que repetem, porque não sabem ler nem escrever, para que possam frequentar o Acelera Brasil e, depois, retornar à rede regular. (INSTITUTO AYRTON SENNA, 2010)

Dando continuidade à análise, das matrículas referentes aos anos iniciais do Ensino Fundamental (216.021), 64,4\% são provenientes das redes municipais de ensino; das matrículas referentes aos anos finais do Ensino Fundamental (165.790), 44,7\% são provenientes das redes municipais de ensino e 42,2\% da rede estadual de ensino.

Existem 102.909 matrículas no Ensino Fundamental rural em Sergipe, o que representa $27 \%$ do 
total de matrículas. Destas, 72.437 referem-se a matrículas nos anos iniciais (70,4\%). Além disso, as matrículas no Ensino Fundamental rural concentram-se nas redes municipais de ensino (93,4\%).

Chama a atenção, devido à sua especificidade, a quantidade de estabelecimentos rurais de Ensino Fundamental: 1.250 , o que representa $58,2 \%$ dos estabelecimentos que oferecem Ensino Fundamental no estado. 94,8\% dos estabelecimentos rurais que oferecem Ensino Fundamental são da rede municipal de ensino.

O desmembramento do Ensino Fundamental leva à visualização de que há uma concentração dos estabelecimentos de Ensino Fundamental rural nos anos iniciais, ou seja, 98,8\% dos estabelecimentos rurais oferecem os anos inicias e apenas $18,2 \%$ oferecem os anos finais, evidenciando a necessidade de deslocamento dos alunos para outras escolas mais distantes para conseguirem concluir seus estudos.

Tendo em vista a grande incidência de estabelecimentos rurais, cabe destacar que isso implica na existência de um grande número de escolas com poucos alunos. Dos 2.148 estabelecimentos de Ensino Fundamental do estado de Sergipe: 21\% tem até 30 matrículas e $44 \%$ tem de 30 a 150 alunos.

Muitos dos estabelecimentos rurais são multisseriados, ou seja, atendem alunos de diferentes faixas etárias, matriculados em diversos anos do Ensino Fundamental. A esse respeito, pode-se destacar a existência do Programa Escola Ativa do Ministério da Educação, implementado pelas redes municipais e estadual de ensino de Sergipe. (PARENTE, 2010)

O Programa está voltado para classes multisseriadas, combinando uma série de elementos e instrumentos de caráter pedagógico, social e de gestão da escola, com o objetivo de melhorar a qualidade do desempenho escolar em classes multisseriadas das escolas do campo. Entre as suas principais estratégias estão a implantação de recursos pedagógicos nas escolas, que permitam ao aluno desenvolver suas potencialidades através do estímulo de um ambiente que favoreça a construção do conhecimento. O programa utiliza material pedagógico e de kits pedagógicos para viabilizar a consecução de seus objetivos, além de oferecer formação aos professores e gestores, melhorando a qualidade da ação docente. (BRASIL, 2008)

No que se refere à ampliação da jornada escolar, das 16.123 turmas do Ensino Fundamental de Sergipe, apenas 137 tem jornada com mais de 5 horas de duração, totalizando 3.364 matrículas, ou seja, menos de $1 \%$ dos alunos matriculados no Ensino Fundamental.

Desde 2009, a rede estadual de ensino e algumas redes municipais aderiram ao Programa Mais Educação, um programa de ampliação da jornada escolar. O Programa Mais Educação é um programa federal instituído pela Portaria Interministerial $n^{\circ} 17$, de $24 / 04 / 2007$, envolvendo os Ministérios da Educação, do Desenvolvimento Social e Combate à Fome, do Esporte e da Cultura. O Programa tem como objetivo: contribuir para a formação integral de crianças, adolescentes e jovens, por meio da articulação de ações, de projetos e de programas do Governo Federal e suas contribuições às propostas, visões e práticas curriculares das redes públicas de ensino e das escolas, alterando o ambiente escolar e ampliando a oferta de saberes, métodos, processos e conteúdos educativos. (BRASIL, 2007, Art. $1^{\circ}$ )

Finalizando a exposição sobre o atendimento no Ensino Fundamental, pode-se mais uma vez reforçar a importância da formulação e implementação de políticas públicas que dêem conta de minimizar os problemas educacionais atuais no estado de Sergipe.

O Plano Nacional de Educação, no que se refere ao Ensino Fundamental, anuncia 30 metas. Em termos de acesso, ampliação da oferta e fluxo, indica as seguintes necessidades

Universalizar o atendimento de toda a clientela do ensino fundamental, no prazo de cinco anos a partir da data de aprovação deste plano, garantindo o acesso e a permanência de todas as crianças na escola, estabelecendo em regiões em que se demonstrar necessário programas específicos, com a colaboração da União, dos Estados e dos Municípios. Ampliar para nove 
anos a duração do ensino fundamental obrigatório com início aos seis anos de idade, à medida que for sendo universalizado o atendimento na faixa de 7 a 14 anos. 3. Regularizar o fluxo escolar reduzindo em 50\%, em cinco anos, as taxas de repetência e evasão, por meio de programas de aceleração da aprendizagem e de recuperação paralela ao longo do curso, garantindo efetiva aprendizagem. (BRASIL, 2001).

Diante das dificuldades de atingir as metas propostas no PNE, o documento referência da CONAE indica, para o novo Plano, algumas necessidades urgentes: universalização e ampliação do ensino fundamental de 9 anos, superar a ruptura entre os anos iniciais e finais do ensino fundamental, formulação, implementação e acompanhamento de políticas e projetos político-pedagógicos para a expansão da escola em tempo integral. (BRASIL, 2009d).

\section{Formação de Professores: principais desafios}

A Lei de Diretrizes e Bases da Educação Nacional, Lei n ${ }^{\circ} 9.394 / 1996$, determina que

A formação de docentes para atuar na educação básica far-se-á em nível superior, em curso de licenciatura, de graduação plena, em universidades e institutos superiores de educação, admitida, como formação mínima para o exercício do magistério na educação infantil e nas quatro primeiras séries do ensino fundamental, a oferecida em nível médio, na modalidade Normal. (BRASIL, 1996, artigo 62)

Conforme o Plano Nacional de Educação, Lei n ${ }^{\circ}$ 10.172/2001, entre as metas relativas à formação de professores para atuação na Educação Infantil, destacam-se:
Estabelecer um Programa Nacional de Formação dos Profissionais de educação infantil, com a colaboração da União, Estados e Municípios, inclusive das universidades e institutos superiores de educação e organizações não-governamentais, que realize as seguintes metas: (...) que, em cinco anos, todos os professores tenham habilitação específica de nível médio e, em dez anos, 70\% tenham formação específica de nível superior. A partir da vigência deste plano, somente admitir novos profissionais na educação infantil que possuam a titulação mínima em nível médio, modalidade normal, dando-se preferência à admissão de profissionais graduados em curso específico de nível superior. (BRASIL, 2001)

Ainda conforme o PNE, são metas relativas à formação de professores para a Educação Básica:

Garantir que, no prazo de 5 anos, todos os professores em exercício na educação infantil e nas quatro primeiras séries do ensino fundamental, inclusive nas modalidades de educação especial e de jovens e adultos, possuam, no mínimo, habilitação de nível médio (modalidade normal), específica e adequada às características e necessidades de aprendizagem dos alunos. Garantir, por meio de um programa conjunto da União, dos Estados e Municípios, que, no prazo de dez anos, 70\% dos professores de educação infantil e de ensino fundamental (em todas as modalidades) possuam formação específica de nível superior, de licenciatura plena em instituições qualificadas. (IDEM)

Apesar dessas prerrogativas, o fato é que ainda existem muitos professores leigos, ou seja, que 
atuam na educação básica sem a formação mínima exigida pela LDB.

Conforme dados de 2009, existem 23.129 professores atuando na Educação Básica no estado de Sergipe, sendo: 3.863 na Educação Infantil, 17.221 no Ensino Fundamental, 4.584 no Ensino Médio, 230 na Educação Profissional e 3.565 na Educação Especial e 3.761 Educação de Jovens e Adultos. ${ }^{3}$

Dos 23.129 professores $46,3 \%$ pertencem às redes municipais de ensino, 25,3\% pertencem à rede estadual de ensino, $1,1 \%$ à rede federal de ensino, $15,9 \%$ trabalham em instituições particulares e 11,4\% trabalham em mais de uma rede de ensino.

Dos professores que atuam na Educação Básica, 79,4 são do sexo feminino e $20,6 \%$ são do sexo masculino; $31,1 \%$ tem idade entre 41 a 50 anos e $28,1 \%$ tem entre 33 e 40 anos.

No que se refere aos professores que atuam na Educação Infantil, dos 3.863 professores, existem 98 com formação apenas no Ensino Fundamental e 428 tem formação em nível médio, ou seja, 14\% dos professores que atuam na Educação Infantil são leigos. No Brasil, o número de professores que atuam na Educação Infantil com formação apenas no ensino fundamental ou ensino médio é de $10 \%$. (Quadro 1)
Dos 3.863 professores que atuam na Educação Infantil, $42 \%$ tem a formação mínima exigida por lei, em nível médio na modalidade Normal/Magistério, e 44,4\% tem formação em nível superior, com ou sem licenciatura.

Do total de professores com nível superior, $92 \%$ tem licenciatura e $94 \%$ tem formação superior na área de formação de professor e ciências da educação.

Considerando apenas os docentes que atuam nas creches do estado de Sergipe, verifica-se que existem $23 \%$ professores leigos. No Brasil, o número de leigos que atuam nas creches é de 13\%. Na pré-escola, existem $13 \%$ de professores que possuem apenas ensino fundamental e/ou ensino médio, sem magistério e/ou modalidade normal. No Brasil, o número de leigos que atuam na pré-escola é de 9\%.

Nos anos iniciais do Ensino Fundamental existem 9.182 professores. Destes, $1 \%$ possui apenas o Ensino Fundamental como formação e 7\% possui nível médio, totalizando 8\% de professores leigos que atuam nos anos iniciais do Ensino Fundamental. Do total de professores que atuam nos anos iniciais do Ensino Fundamental, 31\% dos professores possuem nível médio/magistério e $61 \%$ tem formação em nível superior. (Quadro 2)

Quadro 1: Professores da Educação Infantil Por Escolaridade, em 2009 - Brasil e Estado de Sergipe

\begin{tabular}{|l|c|c|c|c|}
\hline \multirow{2}{*}{ Nível de Formação } & \multicolumn{2}{|c|}{ Brasil } & \multicolumn{2}{c|}{ Sergipe } \\
\cline { 2 - 5 } & $\mathbf{N}^{\circ}$ Absoluto & Porcentagem & $\mathbf{N}^{\circ}$ Absoluto & Porcentagem \\
\hline Total & 369.698 & - & 3.863 & - \\
\hline Ensino Fundamental & 4.968 & $1 \%$ & 98 & $3 \%$ \\
\hline Ensino Médio & 34.435 & $9 \%$ & 428 & $11 \%$ \\
\hline Ensino Médio Normal/Magistério & 152.567 & $42 \%$ & 1.623 & $42 \%$ \\
\hline Educação Superior & 177.728 & $48 \%$ & 1.714 & $44 \%$ \\
\hline
\end{tabular}

Fonte: Sinopse do Professor, 2009c.

Quadro 2: Professores do Ensino Fundamental - Anos Iniciais - Por Escolaridade, em 2009 - Brasil e Estado de Sergipe

\begin{tabular}{|c|c|c|c|c|}
\hline \multirow[b]{2}{*}{ Nível de Formação } & \multicolumn{2}{|c|}{ Brasil } & \multicolumn{2}{|c|}{ Sergipe } \\
\hline & $N^{0}$ Absoluto & Porcentagem & $N^{0}$ Absoluto & Porcentagem \\
\hline Total & 721.513 & 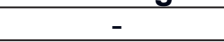 & 9.182 & - \\
\hline Ensino Fundamental & 4.137 & $1 \%$ & 77 & $1 \%$ \\
\hline Ensino Médio & 46.594 & $6 \%$ & 655 & $7 \%$ \\
\hline Ensino Médio Normal/Magistério & 228.699 & $32 \%$ & 2.822 & $31 \%$ \\
\hline Educação Superior & 442.083 & $61 \%$ & 5.628 & $61 \%$ \\
\hline
\end{tabular}

Fonte: Sinopse do Professor, 2009c. 
Dos professores com formação em nível superior, 93\% são licenciados e $86 \%$ possuem formação superior na área de formação de professor e ciências da educação.

Assim, os números relativos aos professores que atuam na Educação Infantil e no Ensino Fundamental indicam a necessidade premente de investimento na formação inicial.

\section{Considerações finais}

A descrição de indicadores educacionais relativos à educação sergipana deve servir para melhor conhecer a realidade educacional, seus problemas e desafios; deve também contribuir para o planejamento, a política e a gestão da educação no estado, na medida em que traz à tona elementos importantes para o conhecimento de suas necessidades educacionais.

O presente estudo também cumpre seu objetivo ao ressaltar a importância de pesquisas no âmbito da política e da gestão educacional do estado de Sergipe, de modo a contribuir para a melhoria da qualidade da oferta educacional, principalmente, no que diz respeito aos seguintes aspectos: ampliação da oferta educacional em todos os níveis e modalidades de ensino; disseminação de experiências de educação integral/ampliação da jornada escolar; desenvolvimento de políticas de formação de professores que congregue formação inicial e continuada.

\section{Notas}

1 Os dados referem-se ao número de matrículas, podendo o aluno ter mais de uma matrícula.

2 Os dados referem-se ao número de estabelecimentos, podendo o mesmo oferecer mais de uma etapa de ensino.

3 O professor pode atuar em mais de um nível/ modalidade de ensino.

\section{Referências Bibliográficas}

ABICALIL, Carlos Augusto. Construindo o sistema nacional articulado de educação. Disponível em: http://conae.mec.gov.br/images/stories/pdf/ const_\%20sae.pdf. Acesso em: 01/06/2010.

BARDACH, Eugene. Los Ocho Pasos para el Análisis de Políticas Públicas: un manual para la prática. 3 ed. México: Miguel Ángel Porrúa, 2001.

BRASIL. Constituição Federal de 1988. Disponível em: http://www.planalto.gov.br/ccivil_03/ constituicao/constitui\%C3\%A7ao.htm. Acesso em: 01/06/2010

Emenda Constituição $\mathbf{n}^{\mathbf{0}} \mathbf{5 3}$, de 19/12/2006. Disponível em: http://www.planalto. gov.br/ccivil_03/constituicao/Emendas/Emc/emc53. htm\#art1. Acesso em: 01/06/2010.

Emenda Constitucional $\mathbf{n}^{\mathbf{0}} \mathbf{5 9}$, de 11/11/2009. (2009e) Disponível em: http:// www.planalto.gov.br/ccivil_03/constituicao/ constitui\%C3\%A7ao.htm. Acesso em: 01/06/2010.

Lei no 9.394, de 20/12/1996. Disponível em: http://www.planalto.gov.br/ccivil_03/Leis/ L9394.htm. Acesso em: 01/06/2010.

Lei $\mathbf{n}^{\mathbf{o}} \mathbf{1 0 . 1 7 2}$, de 09/01/2001. Disponível em: http://www.planalto.gov.br/ccivil_03/leis/ leis_2001/l10172.htm. Acesso em: 01/06/2010.

Lei no 11.274, de 06/02/2006. Disponível em: http://www.planalto.gov.br/ccivil_03/_Ato20042006/2006/Lei/L11274.htm\#art3. Acesso em: 01/06/2010.

Portaria Interministerial $n^{\circ} 17$, de 24/04/2007. (2007a) Institui o Programa Mais Educação, que visa fomentar a educação integral de crianças, adolescentes e jovens, por meio do apoio a atividades sócio-educativas no contraturno escolar. Disponível em: http://portal.mec. gov.br/index.php?option=com_content\&view= article\&id $=14887 \&$ Itemid $=817$. Acesso em: 01/06/2010.

Ministério da Educação. O Plano de 
Desenvolvimento da Educação: razões, princípios e programas. Brasília: MEC, 2007b.

\section{Conferência Nacional de Educação}

- CONAE 2010. Construindo o Sistema Nacional Articulado de Educação: o Plano Nacional de Educação, Diretrizes e Estratégias de Ação. Documento Referência. Brasília: MEC, 2009d. Disponível em: http://portal.mec.gov.br/arquivos/pdf/conae/documento_referencia.pdf. Acesso em: 01/06/2010.

Conferência Nacional de Educação

- CONAE 2010. Construindo o Sistema Nacional Articulado de Educação: o Plano Nacional de Educação, Diretrizes e Estratégias de Ação. Documento Final. Brasília: MEC, 2010. Disponível em: http:// conae.mec.gov.br/images/stories/pdf/pdf/doc_base_ documento_final.pdf. Acesso em: 01/06/2010.

Secretaria de Educação Continuada, Alfabetização e Diversidade. Projeto Base. Brasília: SECAD/MEC, 2008.

Ministério do Planejamento, Orçamento e Gestão. (2009a) Instituto Brasileiro de Geografia e Estatística. Disponível em: http://www.ibge.gov. br/estadosat/temas.php?sigla $=$ se\&tema $=$ sis_2009. Acesso em: 01/06/2010.

. Instituto Nacional de Estudos e Pesquisas Educacionais Anísio Teixeira. Sinopse Estatística da Educação Básica - 2009. (2009b) Disponível em: http://www.inep.gov.br/basica/censo/Escolar/ Sinopse/sinopse.asp. Acesso em: 01/06/2010.

Sinopse do Professor - 2009. (2009c)

Disponível em: http://www.inep.gov.br/basica/censo/ Escolar/Sinopse/sinopse.asp. Acesso em: 01/06/2010.

CAMARGO, Rubens Barbosa de; PINTO, José Marcelino de Rezende; GUIMARAES, José Luiz. Sobre o Financiamento no Plano de Desenvolvimento da Educação. Cadernos de Pesquisa, São Paulo, v. 38, n. 135, dez. 2008. Disponível em <http://www. scielo.br/scielo.php?script=sci_arttext\&pid=S0100 $-15742008000300014 \& \operatorname{lng}=p t \& n r m=i s o>$. Acesso em: 01/06/2010.

CURY, Carlos Roberto Jamil. A educação Básica no Brasil. Educação \& Sociedade. São Paulo: Cortez; Campinas: Cedes, Vol. 23, n. 80. Set. 2002, p. $169-201$.

FÁVERO, Osmar (org.). A Educação nas Constituintes Brasileiras 1823-1988. Campinas: Autores Associados, 1996.

INSTITUTO AYRTON SENNA. Programas Se Liga e Acelera. Disponível em: http://senna.globo. com/institutoayrtonsenna/br/programas_home.asp. Acesso em: 01/06/2010.

LIBÂNEO, José Carlos; OLIVEIRA, João Ferreira de; TOCHI, Mirza SEABRA. Educação escolar: políticas, estrutura e organização. Ed. São Paulo: Cortez, 2007.

PARENTE, Cláudia da Mota Darós. A construção dos tempos escolares: possibilidades e alternativas plurais. Tese (Doutorado em Educação). Universidade Estadual de Campinas, Faculdade de Educação, Campinas, 2006.

O Programa Escola Ativa do Ministério da Educação: política pública para as escolas multisseriadas. Anais do X Encontro de Pesquisa em Educação da ANPED Centro-oeste: desafios da produção e divulgação do conhecimento, 2010, Uberlândia. Uberlândia- MG: FACED/UFU, 2010. v.1. p.1 - 482 .

ROMANELLI, Otaíza de Oliveira. História da Educação no Brasil 1930-1973. 23 ed. Petrópolis, RJ: Vozes, 1999.

RUS PEREZ, José Roberto; NASCIMENTO, Maria Evelyna Pompeu do; PARENTE, Cláudia da Mota Darós. Informe OEI-Ministério 2002-Sistemas Educativos Nacionales - Brasil. INEP/MEC, 2002. Disponível em: http://www.oei.es/quipu/brasil/index.html

SANCHES, Carlos Ruiz. Manual para la Elaboración de Políticas Públicas. 2 ed. México: Plaza y Valdes Editora, 2002.

SAVIANI, Demerval. A Nova Lei da Educação: trajetória, limites e perspectivas. 10. ed. rev. Campinas, SP: Autores Associados, 1997.

Da Nova LDB ao Novo Plano Nacional 
de Educação: por uma outra política educacional. Campinas: Autores Associados, 1998.

Da Nova LDB ao FUNDEB: por uma outra política educacional. Campinas, SP: Autores Associados, 2007.

Sistema de Educação: subsídios para a Conferência Nacional de Educação. Disponível em: http://conae.mec.gov.br/images/stories/pdf/ conae_dermevalsaviani.pdf. Acesso em: 01/06/2010. VEIGA, Cynthia Greive. História da Educação. São Paulo: Ática, 2007.

VIANA, Ana Luiza. Abordagens Metodológicas em Políticas Públicas. Cadernos de Pesquisa, 5. Núcleo de Estudos de Políticas Públicas. Campinas, SP: UNICAMP, 1988.

\section{Sobre os autores:}

Cláudia da Mota Darós Parente: Doutora em Educação pela Faculdade de Educação da Universidade Estadual de Campinas (UNICAMP); Professora Adjunta do Departamento de Educação do Campus Prof. Alberto Carvalho da Universidade Federal de Sergipe (UFS); Líder do Grupo de Pesquisa em Avaliação, Política, Gestão e Organização da Educação (APOGEU).

E-mail: claudiadaros@hotmail.com

Juliano Mota Parente: Doutorando em Educação pela Universidade do Estado da Bahia; Professor Substituto do Departamento de Educação do Campus Prof. Alberto Carvalho da Universidade Federal de Sergipe; Membro dos Grupos de Pesquisa em Avaliação, Política, Gestão e Organização da Educação APOGEU e do Núcleo de Estudos e Pesquisa em Gestão Educacional e Formação de Gestores - NUGEF. E-mail: julianoparente@uol.com.br 
